\title{
Educational Game Design for Improving the Children with Number Sense
}

\author{
Huda Zaki Naji ${ }^{1}$,Hazim Majeed Jasim ${ }^{2}$ \\ University Sains Malaysia, School of Distance Education, 11800, Penang, Malaysia \& University of Basrah, \\ College of Science, Department of Mathematics, Basrah, Iraq \\ University Utara Malaysia, School of Computing, College of Arts and Sciences, Sintok, Malaysia
}

\begin{abstract}
Number sense is the general comprehension of numbers, operations, and the relationships which involve numbers. Based on previous prevalence studies, there are about 3-6\% of the population who have disabilities to understand the number sense. Thus, the computer technologies and mobile games play an essential role to develop the students with number sense, as it will be a tools to improve their mathematical and logical thinking. The main goal of this paper is to design a new educational math game named as $123 \mathrm{GO}$ to develop a basic mathematical skills of students with number sense. This study explores the measuring consideration for the usability of proposed educational math game (123GO) by using the usability testing which adopted to assess student's motivation towards learning basic mathematical skills. During the usability testing session, the data observations of students are recorded. The usability testing data were quantified to measure the effectiveness, efficiency and satisfaction. The results showed that students' interest when using this game to teach them basic mathematical skills.
\end{abstract}

Keywords: Number Sense, Mathematical Skills, Educational Games, Computer Technologies.

\section{INTRODUCTION}

In the field of education, number sense is the general comprehension of quantity involving zero, fractional and whole units that enables us to articulate quantitative relationships [1-3] Number sense has been considered as one of the fundamental topics in mathematics education $[4,5]$ Thus, number sense helps children develop logical thinking and eliminates their fear of mathematics $[6,7]$. The majority of scholars concur that if students do not understand the fundamentals about the number sense, they cannot realize the basics of mathematics learning and its application in everyday life [8].

Therefore, mathematics educators have found that student's inflexibility in handling number sense problems may be related to the inappropriate design of mathematics textbooks and the rule-based instruction of school mathematics $[9,10]$. previous reports and studies have strongly suggested that technologies and mobile games should be integrated into mathematics teaching and learning, since these technologies are a promising means for providing conceptual understanding [11]. Integration of technologies into mathematics classroom settings can enhance student's mathematics learning, since the technologies can provide dynamic visualization and interactivity that can help student learn mathematics effectively [12].

Moreover, Olive and Lobato [13] pointed out that the technological tools enhance conceptual understanding of students that can be a very powerful aid to student's learning. Thus, computer technologies and mobile games play an essential role to develop the students with number sense, as it will be a tool to improve their mathematical and logical thinking.

\section{MOBILE DEVICES GAME AND MATHEMATICS LEARNING}

Several studies have indicated on importance of using mobile devices and touch screens for the purpose of teaching children suffering from number sense [14]. Due to the small size of the device's screen that helps students to focus the attention and provides a more intuitive interaction [14]. Mobile devices game has been regarded as an important and effective learning tool for helping students for promoting and understanding the mathematical skills [15]. Where, mobile devices games enable the students with number sense to learn while playing with games that make them more interested [16]. Mobile devices with educational games also help the students with number sense to feel more relaxed doing the activities [17].

However, few studies have focused on using mobile devices games to help students develop number sense [6]. For example, the study of Su et al. [18] showed that webbased tools could be used to reinforce primary school children's number sense. Also, the study of Yang and Tsai [6] applied the technologies-based environment to help teacher's teaching and student's learning in number sense. In addition, Clark and Mayer [7] focused only on used the words to teach the children counting and guessing without 
Vol. 5, Issue 9, September 2016

considering that merging of figures, words, and visuals with formulas enhances the illustration side to teach counting and guess of number sense [7]. Moreover, there are many difficulties to use these mobile games that appear with some limited features [19]. Where, these games are not compatible with overall symptoms of number sense, especially related with the user interface design, a language and the busy screen [20].

\section{III.METHODOLOGY}

In this paper the design and development of $123 \mathrm{GO}$ game was aimed to assist with basic skill instruction in the areas of write and pronounce numbers, account, number after, number before and maximum (minimum) numbers. To design and development (123GO), the following activities with specific methods have been conducted: design the prototype, participants and measuring usability testing.

\section{A. Design the Prototype}

This stage includes the development and implementation of the prototype. The design occurs first whereby at this point the main task is to make sure that the functions exist in a good arrangement with good case, active, sequence, class and state diagrams under the correct category of artifacts. A database design also will be added for refinement. This paper makes use of Rapid Application Development methodology (RAD) to develop the prototype. According to Whitten [21], RAD is a merger of various structured techniques, especially data-driven Information Engineering, with prototyping techniques to accelerate software systems development [21]. Where, structured techniques and prototyping are often used in RAD to define users' requirements and design the final system.

The prototype mentioned in this paper requires conditions as indicated in the Table 1, which facilitates the work and enables interaction with the users. We will refer to apps that make use of Android platforms [22], which is an operating system often employed on mobile devices like smart phones and tablets. Also, we used Eclipse tool for Java language for developing the prototype in the same Java language and environment. Lastly, the providers of the content will create a custom interface to store and retrieve different kinds of data stores like SQLite databases [23].

\section{TABLE 1 PROTOTYPE DEVELOPMENT ENVIRONMENT}

\begin{tabular}{|c|c|}
\hline \multicolumn{2}{|c|}{ Prototype Development Environment } \\
\hline Program language & Eclipse tool for Java language \\
\hline Operating system & Android platform \\
\hline Database & SQLite \\
\hline
\end{tabular}

Essentially, the $123 \mathrm{GO}$ mobile application has been released with two different languages which are Malay and English language. Malaysian language is a default language for the application's appearance. The 123GO mobile application provides an interface with the couple of choices for presenting language. Hence, the users can switch between the languages by selecting a specific language and press on "Select" button from this page. The application will respond to users' activity and display the home page with selected language. Figure 1 below shows the interface language page with both of application languages.

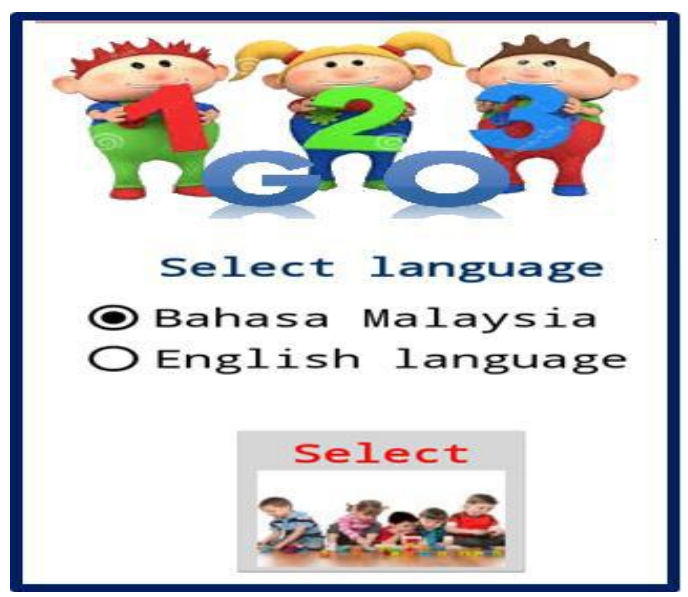

Fig. 1 Description the interface of $123 \mathrm{GO}$ App with both of application languages

The home page is a main gate to use the functions of the prototype which has two core functions that represents the levels of mathematic learning. These functions are display in English language by: Beginner function and Advance function, at the same time they display in Malay language by: Mudah and Sukar. The actor can deal with every function of application by pressing on its icon thus, the prototype displays the page of selected function. Figure 2 shows the home page of $123 \mathrm{GO}$ app.

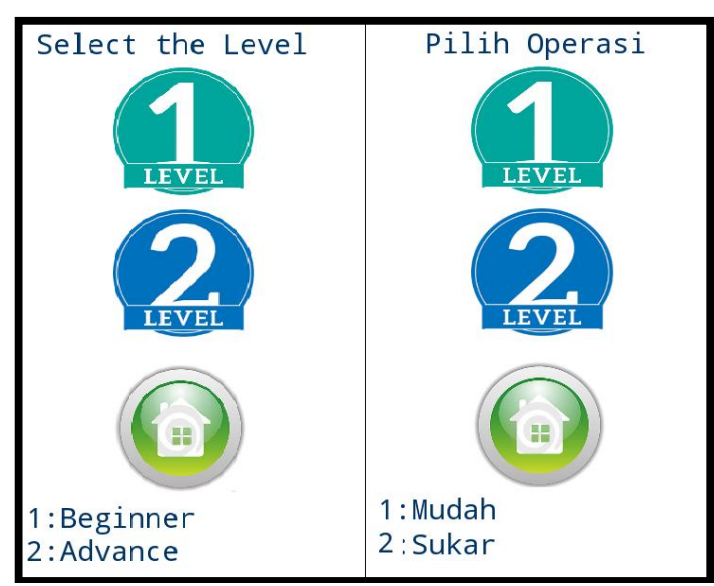

Fig. 2 Description the home page of $123 \mathrm{GO}$ App

- Beginner (Mudah) function: is a first level of learning for this prototype that deal with teaching students the counting, writing and pronunciation the numbers. This is done through the use of colors and integrated audioeffects. Figure 3 below shows the details of this function. 
Vol. 5, Issue 9, September 2016

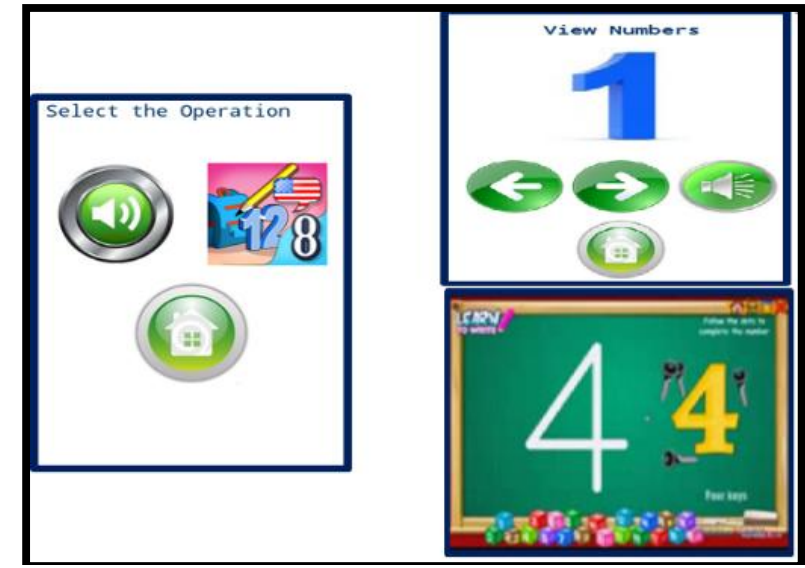

Fig. 3 Description the details of beginner function

- Advance (Sukar) function: is a second function of prototype which develops to teach students the value place of numbers for example, maximum and minimum moreover arranging the numbers in ascending and descending order (number after and number before). An Advance function page contents five buttons which are: Min button, Max button, number after button, number before button and home button. Figure 4 below shows the details of this function.

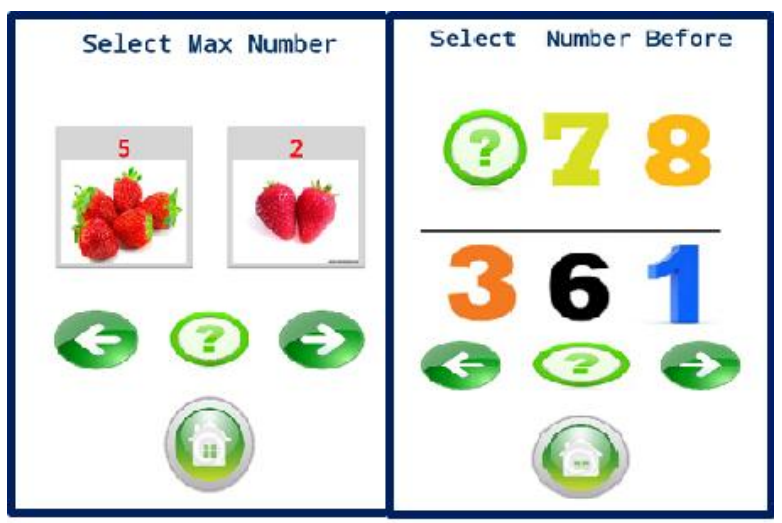

Fig. 4 Description the details of advance function

\section{B. Participants}

A number of 5 students with number sense, aged between 7 to 9 years old, are randomly chosen to participate in the study. Most of them are from middle class family whose parents are mostly self-employed. The study was conducted in a public primary school at Alor Setar, Kedah, Malaysia that offers special number sense classes for the students. We have done the observations to a group of number sense students, in order to conduct the usability tests involved in this paper.

\section{Measuring Usability Testing}

A One of this paper's objectives was to measure the level of efficiency, efficacy, and satisfaction of the 123GO game. The International Organization for Standardization (ISO) [24], defines a usability test as the extent to which a product can be utilized by certain users to achieve specific goals with efficiency, satisfaction, and effectiveness, given a specific context. This definition has three important components:

- Effectiveness: The completeness and accuracy of the manner by which customers achieve specified goals.

- Efficiency: A goal's completeness and accuracy in relation to the resources.

- Satisfaction: Being freed from discomfort and possessing positive attitudes towards system use.

Given the definition of usability, it is apparent that effectiveness and efficiency are two components that have objective characteristics. On the other hand, satisfaction is more subjective. Therefore, measurement of the metrics for effectiveness and efficiency can be done by using a usability measurement that was introduced by Nielsen [25]. Doing so involves measuring and analysing the user's success rate, which is the simplest usability metric.

\section{i. The Results of Effectiveness}

The ability of the user to complete a task in the application is measured by effectiveness [26]. In this study, effectiveness was measured at each interface, and each interface represented the game levels. There was a list of all the tasks that had to be completed. A task that was successfully completed was marked with a 'Yes'. A full credit of $100 \%$ was given to every success mark. A 'No' mark was given to tasks that were not successfully completed. 'No' marks have zero $0 \%$ credit. Table 2 below describes the effectiveness analysis.

\section{TABLE 2 SUMMARY OF THE EFFECTIVENESS ANALYSIS}

\begin{tabular}{|c|c|c|c|c|c|c|}
\hline Answer & $\begin{array}{c}\text { Child } \\
1\end{array}$ & $\begin{array}{c}\text { Child } \\
2\end{array}$ & $\begin{array}{c}\text { Child } \\
3\end{array}$ & $\begin{array}{c}\text { Child } \\
4\end{array}$ & $\begin{array}{c}\text { Child } \\
5\end{array}$ & Subtotal \\
\hline Yes & 21 & 17 & 20 & 20 & 21 & 99 \\
\hline Partial & 1 & 3 & 2 & 1 & 1 & 8 \\
\hline No & 0 & 2 & 0 & 1 & 0 & 3 \\
\hline \multicolumn{8}{|c|}{ Total } \\
\hline
\end{tabular}

The equation shown below was used to compute the overall effectiveness rating for this set of tasks [27]: Effectiveness $(\%)=($ Yes $+($ Partial $\times 0.5)) /$ Total $\times 100 \%$ $=(99+(8 \times 0.5)) / 110 \times 100 \%=93.64 \%$

Using the equation above, the usability testing for the children revealed that the 123GO's effectiveness rating is approximately $93.64 \%$.

ii. The Results of Efficiency

The smoothness of task completion is measured by the efficiency. The method and algorithm used in measuring efficiency is the same as the one used for measuring effectiveness. A smoothly completed task is marked with a 'Yes'. Again, a success mark has a full $100 \%$ credit. A 'No' mark is given for tasks that are not completed smoothly. Zero $0 \%$ credits are awarded to 'No' marks. Table 3 below describes the efficiency analysis. 
Vol. 5, Issue 9, September 2016

TABLE 3 SUMMARY OF THE EFFICIENCY ANALYSIS

\begin{tabular}{|c|c|c|c|c|c|c|}
\hline Answer & Child & Child & Child & Child & Child & Subtotal \\
& 1 & 2 & 3 & 4 & 5 & \\
\hline Yes & 11 & 11 & 8 & 12 & 11 & 53 \\
\hline Partial & 1 & 1 & 2 & 0 & 0 & 4 \\
\hline No & 0 & 0 & 2 & 0 & 1 & 3 \\
\hline \multicolumn{7}{|c|}{ Total } \\
\hline
\end{tabular}

The equation below was used to determine the overall efficiency rating for this set of tasks [27]:

Efficiency $(\%)=($ Yes $+($ Partial $\times 0.5)) /$ Total $\times 100 \%$

$$
=(53+(4 \times 0.5)) / 60 \times 100 \%=91.6 \%
$$

Using the above equation, the usability testing with children has led to the computation of a $91.6 \%$ efficiency rating for the $123 \mathrm{GO}$ educational game.

\section{iii. The Results of Satisfaction}

By using the questionnaires, the children's satisfaction ratings were measured. In other words, children are needed to answer these questions after completing all test scenarios. In this paper the questions were adopted from [26] were designed in order to determine how the children felt about the game, how they liked it, and how easy it was for them. Table 4 shows the questionnaire and the children's answers.

\section{TABLE 4 SUMMARY THE QUESTIONNAIRE AND THE CHILDREN'S ANSWERS}

\begin{tabular}{|c|c|c|c|c|c|c|}
\hline Answer & $\begin{array}{c}\text { Child } \\
1\end{array}$ & $\begin{array}{c}\text { Child } \\
2\end{array}$ & $\begin{array}{c}\text { Child } \\
3\end{array}$ & $\begin{array}{c}\text { Child } \\
4\end{array}$ & $\begin{array}{c}\text { Child } \\
5\end{array}$ & Subtotal \\
\hline $\begin{array}{c}\text { Game } \\
\text { was Fun }\end{array}$ & 5 & 5 & 5 & 5 & 4 & 24 \\
\hline $\begin{array}{c}\text { Game } \\
\text { was } \\
\text { easy to } \\
\text { play }\end{array}$ & 4 & 5 & 4 & 5 & 5 & 23 \\
\hline $\begin{array}{c}\text { I like the } \\
\text { game }\end{array}$ & 5 & 5 & 4 & 4 & 4 & 22 \\
\hline $\begin{array}{c}\text { I do not } \\
\text { find } \\
\text { trouble } \\
\text { to } \\
\text { navigate } \\
\text { between } \\
\text { pages }\end{array}$ & 4 & 5 & 5 & 5 & 4 & 23 \\
\hline $\begin{array}{c}\text { The } \\
\text { selection } \\
\text { of easy } \\
\text { answers }\end{array}$ & 5 & 4 & 5 & 5 & 5 & 24 \\
\hline $\begin{array}{c}\text { I want to } \\
\text { play this } \\
\text { game } \\
\text { again }\end{array}$ & 5 & 5 & 5 & 5 & 5 & 25 \\
\hline $\begin{array}{c}\text { I would } \\
\text { like to } \\
\text { play this } \\
\text { game at } \\
\text { home }\end{array}$ & 5 & 5 & 5 & 5 & 5 & 25 \\
\hline & & Total & & & & \\
\hline
\end{tabular}

\section{IV.CONCLUSION}

The main point of the paper is to design an educational game named as $123 \mathrm{GO}$ that aims to remove barriers to learn the mathematical skills for students with number sense. The prototype also has an interfaces that can make it easier for the students to calculate and find the answers. While the prototype has a colorful graphics that help students to increase their understanding when selecting the answers. Also, the usability test using observation method on $123 \mathrm{GO}$ was done successfully involving students as the test user. From the observation, rating for effectiveness and efficiency can be measured by analyzing user's success rate.

Based on the analysis of the success rate, we found that level of effectiveness in $123 \mathrm{GO}$ is $73 \%$ and level of efficiency is $64 \%$. On the other hand, analysis the questionnaire shows the level of satisfaction is $82 \%$. By averaging rates of effectiveness, efficiency and satisfaction, we can say that usability level for $123 \mathrm{GO}$ is $73 \%$. The outcome of usability test is $93.36 \%$ showed that the prototype is beneficial and convenient for students with number sense to develop their mathematical skills.

\section{REFERENCES}

[1] Malofeeva, E., J. Day, X. Saco, L. Young, and D. Ciancio, "Construction and evaluation of a number sense test with Head Start Children", Journal of Educational Psychology, Vol. 96, No. 4, 2004, pp. 648-659.

[2] Berch, D. B, "Making sense of number sense implications for children with mathematical disabilities", Journal of learning disabilities, Vol. 38 No. 4, 2005, pp. 333-339.

[3] Jordan, N. C. Glutting, J. and Ramineni, "A number sense assessment tool for identifying children at risk for mathematical difficulties", Mathematical difficulties: Psychology and intervention, 2008, pp 45-58.

[4] Dunphy, E, "The primary mathematics curriculum: Enhancing its potential for developing young children's number sense in the early years at school", Irish Educational Studies, Vol. 26, No. 1, 2007, pp. 5-25.

[5] Jordan, N. C. Glutting, J. and Ramineni, "The importance of number sense to mathematics achievement in first and third grades", Learning and Individual Differences, Vol. 20, No. 2, 2010, pp. 82-88.

[6] Yang, D. C. and Tsai, Y. F, "Promoting sixth graders"e number sense and learning attitudes via technology-based environment", Educational Technology and Society, Vol. 13, No. 4, 2010, pp. 112125 .

[7] Clark, R. C. and Mayer, R. E, "Learning by viewing versus learning by doing: Evidence- based guidelines for principled learning environments", Performance Improvement, Vol. 47, No. 9, 2008, pp. 5-13.

[8] Butterworth, B. and Laurillard, "Low numeracy and dyscalculia: identification and intervention", ZDM Mathematics Education, Vol. 42, No. 6, 2010, pp. 527-539.

[9] Menon, R, "Elementary school children's number sense", International Journal for Mathematics Teaching and Learning, Vol. 57, 2004, pp. 1-16.

[10] Yang, D. C. and Li, M. N, "Assessment of Animated Self-Directed Learning Activities Modules for Children's Number Sense Development", Journal of Educational Technology \& Society, Vol. 16, No. 3, 2013, pp. 44- 58.

[11] Dick, T, "Keeping the faith: Fidelity in technological tools for mathematics education", Research on technology and the teaching and learning of mathematics: Syntheses, cases, and perspectives, Vol. 2, 2007, pp. 333-339. 
[12] Gegner, J. A. Mackay, D. H. J. and Mayer, R. E, "Computersupported aids to making sense of scientific articles: cognitive, motivational, and attitudinal effects", Education Technology Research Development, Vol. 57, No. 1, 2009, pp. 79-97.

[13] Olive, J. and Lobato, J, "The learning of rational number concepts using technology", Research on technology and the teaching and learning of mathematics: Research syntheses, Vol. 1, 2008, pp. 153.

[14] Baccaglini-Frank, A. and Maracci, M, "Multi-Touch Technology and Preschoolers" Development of Number-Sense", Digital Experiences in Mathematics Education, 2015, pp. 1-21.

[15] Bennison, A. and Goos, M, "Learning to teach mathematics with technology: A survey of professional development needs, experiences and impacts", Mathematics Education Research Journal, Vol. 22, No. 1, 2010, pp. 31-56.

[16] Yang, D. C. and Li, M. N, "Assessment of Animated Self-Directed Learning Activities Modules for Children's Number Sense Development", Educational Technology \& Society, Vol. 16, No. 3, 2013, pp. 44-58.

[17] Mohd Syah, N. E. Hamzaid, N. A. Murphy, B. P. and Lim, "Development of computer play pedagogy intervention for children with low conceptual understanding in basic mathematics operation using the dyscalculia feature approach", Interactive Learning Environments, 2015, pp. 1-20.

[18] Su, H. F. Marinas, C. and Furner, J. M, "Connecting the numbers in the primary grades using an interactive tool", Australian Primary Mathematics Classroom, Vol. 15, No. 1, 2010, pp. 25-28.

[19] De Castro, M. V. Bissaco, M. A. S. Panccioni, B. M. Rodrigues, S. C. M. and Domingues, "Effect of a virtual environment on the development of mathematical skills in children with dyscalculia", 2014.

[20] Poobrasert, O. and Gestubtim, W, "Development of assistive technology for students with dyscalculia", e-Learning and eTechnologies in Education (ICEEE), 2013 Second International Conference, 2013, pp. 60-63.

[21] Whitten, Jeffrey L. Lonnie D. Bentley, Kevin C. and Dittman, "Systems Analysis and Design Methods", 6th edition, 2004. ISBN 025619906X.

[22] Simm, W. Ferrario, M. A. Gradinar, A. and Whittle, "Prototyping'clasp': implications for designing digital technology for and with adults with autism", Proceedings of the conference on Designing interactive systems, June, 2014, pp. 345-354.

[23] Abdulwahid, H. S, "Requirements for redesigning the interface of Iraqi e- government portal", $\mathrm{PhD}$. Thesis, 2015.

[24] International Organization for Standardization (ISO) "Ergonomic Requirements for Office Work with Visual Display Terminals (VDTs)", Part 11, 1998.

[25] Nielsen, J, "First Rule of Usability? Don't Listen to Users", August 5,2001

[26] Rubin, J. and Chisnell, "How to Plan, Design, and Conduct Effective Tests", Handbook of Usability Testing, 2008.

[27] Ismail, M. Diah, N. M. Ahmad, S. Kamal, N. A. M. and Dahari, "Measuring usability of educational computer games based on the user success rate", Humanities, Science \& Engineering Research (SHUSER), International Symposium, June, 2011, pp. 56-60. 